ARTICLE

\title{
Partially sintered copper-ceria as excellent catalyst for the high-temperature reverse water gas shift reaction
}

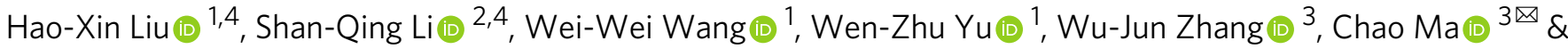
Chun-Jiang Jia (10) ${ }^{1 \times}$

For high-temperature catalytic reaction, it is of significant importance and challenge to construct stable active sites in catalysts. Herein, we report the construction of sufficient and stable copper clusters in the copper-ceria catalyst with high Cu loading (15 wt.\%) for the high-temperature reverse water gas shift (RWGS) reaction. Under very harsh working conditions, the ceria nanorods suffered a partial sintering, on which the $2 \mathrm{D}$ and $3 \mathrm{D}$ copper clusters were formed. This partially sintered catalyst exhibits unmatched activity and excellent durability at high temperature. The interaction between the copper and ceria ensures the copper clusters stably anchored on the surface of ceria. Abundant in situ generated and consumed surface oxygen vacancies form synergistic effect with adjacent copper clusters to promote the reaction process. This work investigates the structure-function relation of the catalyst with sintered and inhomogeneous structure and explores the potential application of the sintered catalyst in $\mathrm{C} 1$ chemistry.

\footnotetext{
${ }^{1}$ Key Laboratory for Colloid and Interface Chemistry, Key Laboratory of Special Aggregated Materials, School of Chemistry and Chemical Engineering, Shandong University, Jinan 250100, China. ${ }^{2}$ Key Laboratory of Micro-Nano Powder and Advanced Energy Materials of Anhui Higher Education Institutes, Chizhou University, Chizhou 247000, China. ${ }^{3}$ College of Materials Science and Engineering, Hunan University, Changsha 410082, China. ${ }^{4}$ These authors

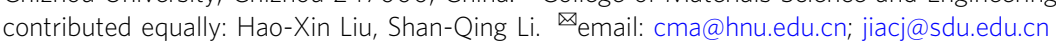


S upported metal catalysts have been widely used in the industrial catalysis process because of their adequate active sites and high atom utilization ${ }^{1-5}$. Recently, nanoengineering has been widely applied on the preparation of solid catalysts with a homogeneous surface structure by anchoring active metal on stable supports ${ }^{6,7}$. Maintaining the uniformity and high dispersion of the active metal sites has been considered to be the key to the excellent activity of catalysts ${ }^{8}$. However, with the sintering of catalysts, the active metal tends to agglomerate especially under the reaction conditions of high temperature and reducing atmosphere, leading to the serious deactivation ${ }^{9,10}$. Reducing the loading of the active metal can partly overcome the aggregation, however, the activity of the catalyst is commonly unsatisfactory due to the insufficient active metal sites ${ }^{11}$. Thus, the construction of stabilized and adequate active sites in the sintered catalyst is a great challenge but also full of significance.

The reverse water gas shift (RWGS) reaction is recognized a most promising way to utilize $\mathrm{CO}_{2}$, thanks to its high selectivity and low operation pressure ${ }^{12-15}$. The resulting $\mathrm{CO}$ is considered as feedstock to produce various value-add chemicals via FischerTropsch synthesis or other syngas process ${ }^{16-18}$. Due to its endothermic property, a high working temperature is usually required to facilitate the equilibrium conversion of $\mathrm{CO}_{2}$. However, it brings huge difficulty to the durability of the catalysts under such harsh conditions $s^{14,19,20}$. Noble metal catalysts, such as Pd- and Pt- based catalysts $11,21,22$, have been studied for this reaction, however, their practical applications are limited by the inferior catalytic performance and high cost. Among the nonnoble metal catalysts, Cu-based catalyst has been considered as the ideal candidate for this reaction because of the high activity, selectivity, and low cost $13,14,23,24$. However, on one hand, the catalysts with high copper loading are apt to agglomeration, causing severe deactivation ${ }^{24}$. On the other hand, the low copper loading on supports can partly resist aggregation, but suffers from insufficient active sites and poor catalytic performance ${ }^{7}$. As a result, the conflict between high activity and high stability under harsh reaction conditions limits the development and application of $\mathrm{Cu}$-based catalysts. According to the previous work, ceria $\left(\mathrm{CeO}_{2}\right)$ is often recognized as a suitable supports to anchor copper because of the strong interaction between copper and ceria. Using the interaction, the copper-ceria catalyst has shown its unique value in a variety of catalytic reactions, such as lowtemperature water-gas shift reaction ${ }^{25,26}, \mathrm{CO}$ oxidation $^{27}$, and $\mathrm{CO}_{2}$ hydrogenation ${ }^{23,28}$. Besides, $\mathrm{CeO}_{2}$ tends to sintered after high-temperature aging, resulting in a dramatic structural transformation ${ }^{29}$. Recently, our group has constructed stable and atomically dispersed copper site with unsaturated coordination in the sintered copper-ceria catalyst with very low $\mathrm{Cu}$ loading of $1 \mathrm{wt} \%$ by air-calcination at $800^{\circ} \mathrm{C}$, which exhibited very high and stable activity for $\mathrm{CO}$ oxidation ${ }^{27}$. However, during the long-term harsh reaction conditions of high temperature and reductive atmosphere, the structure of the copper-ceria catalyst is still unclear, especially for the catalyst with relative high copper loading, which undoubtedly limits the development and application of the copper-ceria catalyst.

Herein, we report a partially sintered $\mathrm{Cu} / \mathrm{CeO}_{2}$ catalyst with $\mathrm{Cu}$ loading up to $15 \mathrm{wt} \%$ which exhibits extraordinarily high activity and stability for the RWGS reaction under very harsh conditions $\left(600^{\circ} \mathrm{C}\right.$, space velocity of $\left.400,000 \mathrm{~mL} \cdot \mathrm{g}_{\mathrm{cat}}{ }^{-1} \cdot \mathrm{h}^{-1}\right)$. Two-dimensional (2D) and three-dimensional (3D) copper clusters are formed and firmly anchored on the surface of ceria under the reaction conditions due to the interaction between copper and ceria, through which abundant stable active sites were constructed. Further, structural characterization and DFT calculations confirmed that abundant active surface oxygen vacancies were in situ generated and consumed circularly during the reaction, which combined with adjacent copper clusters to promote the activation of $\mathrm{CO}_{2}$ and catalytic efficiency. The synergistic catalytic effect of anti-sintering active copper clusters and sufficient surface oxygen vacancies provided a guarantee for the extraordinary activity and stability under harsh conditions. The partially sintered catalyst with excellent catalytic performance breaks the conventional impression that catalysts are severely deactivated upon sintering and shows great potential in the utilization of $\mathrm{CO}_{2}$.

\section{Results}

Catalytic performance in the RWGS reaction. The catalytic performance in the RWGS reaction over various catalysts was evaluated at various temperatures under a high space velocity of $400,000 \mathrm{~mL} \cdot \mathrm{g}_{\mathrm{cat}}{ }^{-1} \cdot \mathrm{h}^{-1}$. As shown in Fig. 1a, the $\mathrm{CeO}_{2}$ support itself showed very poor catalytic activity. When the reaction temperature reached $600{ }^{\circ} \mathrm{C}, \mathrm{CO}_{2}$ conversion was only $8 \%$. While, after depositing copper on ceria, the catalyst significantly promoted the catalytic activity. The catalytic activity increased with the increasing of copper loading until the copper loading reached 15 wt.\% (Supplementary Fig. 1). Among all the prepared catalysts, the $15 \mathrm{CuCe}$ catalyst showed the best activity of $146.6 \mathrm{~mol}_{\mathrm{CO} 2} \cdot \mathrm{g}_{\mathrm{cat}}{ }^{-1} \cdot \mathrm{s}^{-1}$ at $600^{\circ} \mathrm{C}$, which was at least three times higher than all the other reported catalysts. In addition, the reaction rate of $15 \mathrm{CuCe}$ was as high as $52.2 \mathrm{~mol}_{\mathrm{CO} 2} \cdot \mathrm{g}_{\mathrm{cat}}{ }^{-1} \cdot \mathrm{s}^{-1}$ at $500{ }^{\circ} \mathrm{C}$, more than one order of magnitude than that of other reported non-noble metal catalysts and even noble metal catalysts (Fig. $1 \mathrm{~b}$ and Table 1). And it is worth noting that these $\mathrm{Cu}$ catalysts show $100 \%$ selectivity of $\mathrm{CO}$ with no $\mathrm{CH}_{4}$ detected in the products (Supplementary Fig. 1b). Besides, the catalytic performances of the $15 \mathrm{CuCe}$ catalyst under other reaction atmospheres with different $\mathrm{H}_{2}: \mathrm{CO}_{2}$ ratios were also evaluated. As shown in Supplementary Fig. 2, the $\mathrm{CO}_{2}$ conversion increased with the increasing of the $\mathrm{H}_{2}: \mathrm{CO}_{2}$ ratio. And at all these $\mathrm{H}_{2}: \mathrm{CO}_{2}$ ratios, the $15 \mathrm{CuCe}$ catalyst shown excellent catalytic activity, suggesting this catalyst had high catalytic efficiency over a wide range of $\mathrm{H}_{2}: \mathrm{CO}_{2}$ ratios. And it was noteworthy that even when the $\mathrm{H}_{2}: \mathrm{CO}_{2}$ ratio reached $4: 1$, no $\mathrm{CH}_{4}$ was detected in the production, which indicated the catalyst catalyzed the RWGS reaction much rather than the methanation. To the best of our knowledge, the excellent activity of the $15 \mathrm{CuCe}$ catalyst at high temperature is unmatched. As shown in Fig. 1c and Supplementary Fig. 3, the apparent activation energy $E_{\mathrm{a}}$ of the $5 \mathrm{CuCe}$ catalyst $\left(62.88 \mathrm{~kJ} \cdot \mathrm{mol}^{-1}\right)$ and the $15 \mathrm{CuCe}$ catalyst $\left(57.92 \mathrm{~kJ} \cdot \mathrm{mol}^{-1}\right)$ was much lower than that of the $15 \mathrm{CuAl}$ catalyst $\left(133.96 \mathrm{~kJ} \cdot \mathrm{mol}^{-1}\right)$. Besides, the $15 \mathrm{CuCe}$ catalyst synthesized with $\mathrm{CeO}_{2}$ nanorod as support exhibited much better activity than that of the $15 \mathrm{CuCe}-\mathrm{NC}$ and $15 \mathrm{CuCe}-\mathrm{NP}$ catalysts, indicating the morphologies of $\mathrm{CeO}_{2}$ supports had important effect on the catalytic performance (Supplementary Fig. 4).

Long-term evaluation of the copper-ceria catalysts was conducted. As illustrated in Fig. 1d, both the $5 \mathrm{CuCe}$ and $15 \mathrm{CuCe}$ catalyst showed excellent stability. For the $5 \mathrm{CuCe}$ catalyst and the $15 \mathrm{CuCe}$ catalyst, even under the very harsh condition $\left(600^{\circ} \mathrm{C}\right.$, $\left.\mathrm{GHSV}=400,000 \mathrm{~mL} \cdot \mathrm{g}_{\mathrm{cat}}{ }^{-1} \cdot \mathrm{h}^{-1}\right)$, it maintained more than $85 \%$ of its initial activity after $70 \mathrm{~h}$ test. The activity of both the $5 \mathrm{CuCe}$ and the $15 \mathrm{CuCe}$ catalysts decreased gradually in the first $20 \mathrm{~h}$ and then stabilized. In order to explore the stability of the $15 \mathrm{CuCe}$ catalyst further, the test time was extended to $240 \mathrm{~h}$, and the $15 \mathrm{CuCe}$ catalyst still showed excellent stability. However, the $15 \mathrm{CuCe}-\mathrm{NP}$ catalyst with more severe sintering (Supplementary Table 1) showed worse stability and lower activity in the $40 \mathrm{~h}$ test (Supplementary Fig. 5). And the reference $15 \mathrm{CuAl}$ catalyst lost more than $50 \%$ of its original activity within $10 \mathrm{~h}$ under the same test conditions. In addition, the reaction rate of the $15 \mathrm{CuCe}$ catalyst decreased slightly after six rounds of start-up cool-down stability tests (Supplementary Fig. 6). From the above results, the 

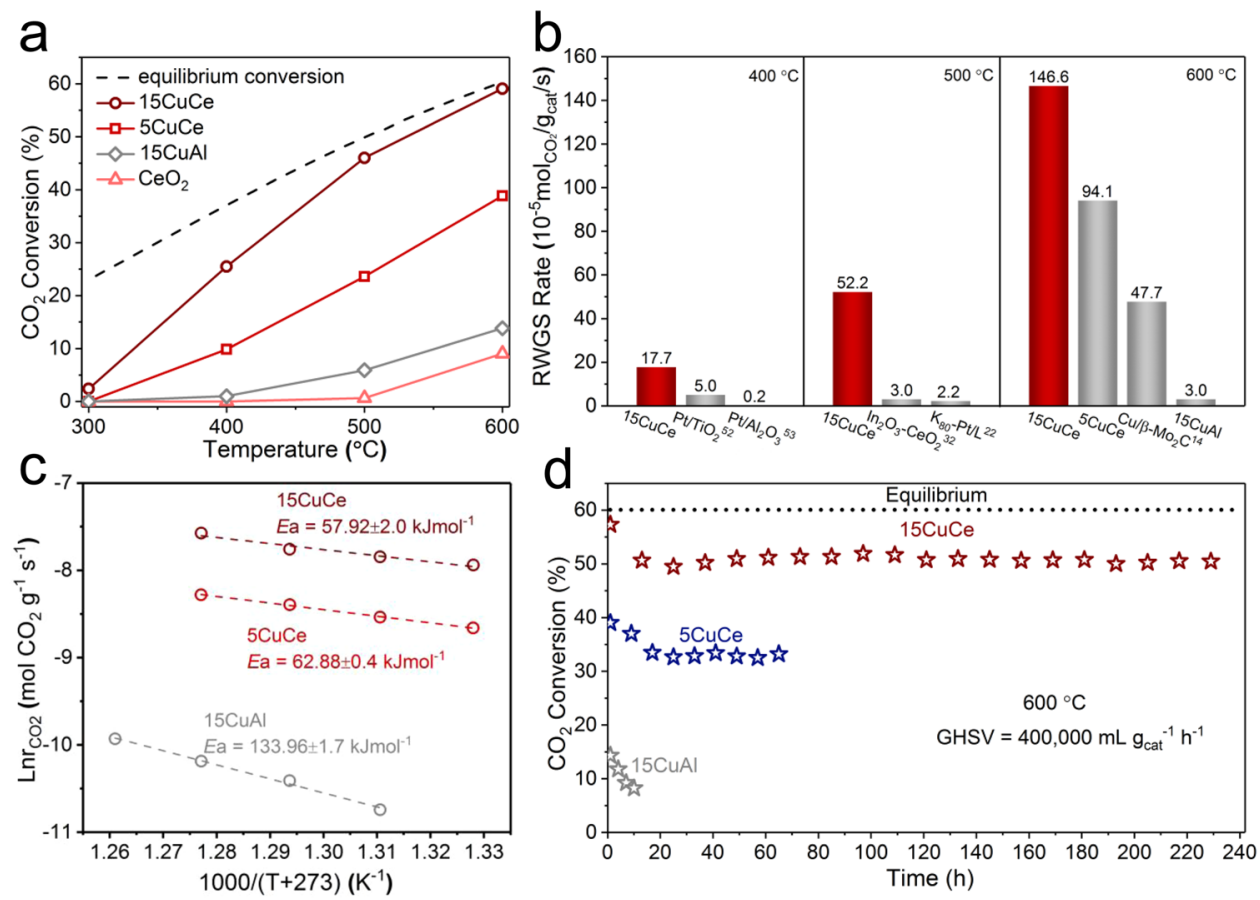

Fig. 1 Catalytic performance of copper-ceira catalysts in RWGS reaction. a Activities of $\mathrm{CeO}_{2}, 5 \mathrm{CuCe}, 15 \mathrm{CuCe}$, and $15 \mathrm{CuAl}$ catalysts; $\mathbf{b}$ Comparison of reaction rates for different catalysts at $400^{\circ} \mathrm{C}, 500^{\circ} \mathrm{C}$, and $600^{\circ} \mathrm{C}$; c Apparent activation energy value of various catalysts; $\mathbf{d}$ Long-term catalytic tests of the $5 \mathrm{CuCe}, 15 \mathrm{CuCe}$ catalysts and the reference $15 \mathrm{CuAl}$ catalyst.

Table 1 Comparison of $\mathrm{CO}_{2}$ Conversion Rate and $\mathrm{CO}$ Selectivity for the as-prepared and Literature Reported catalysts.

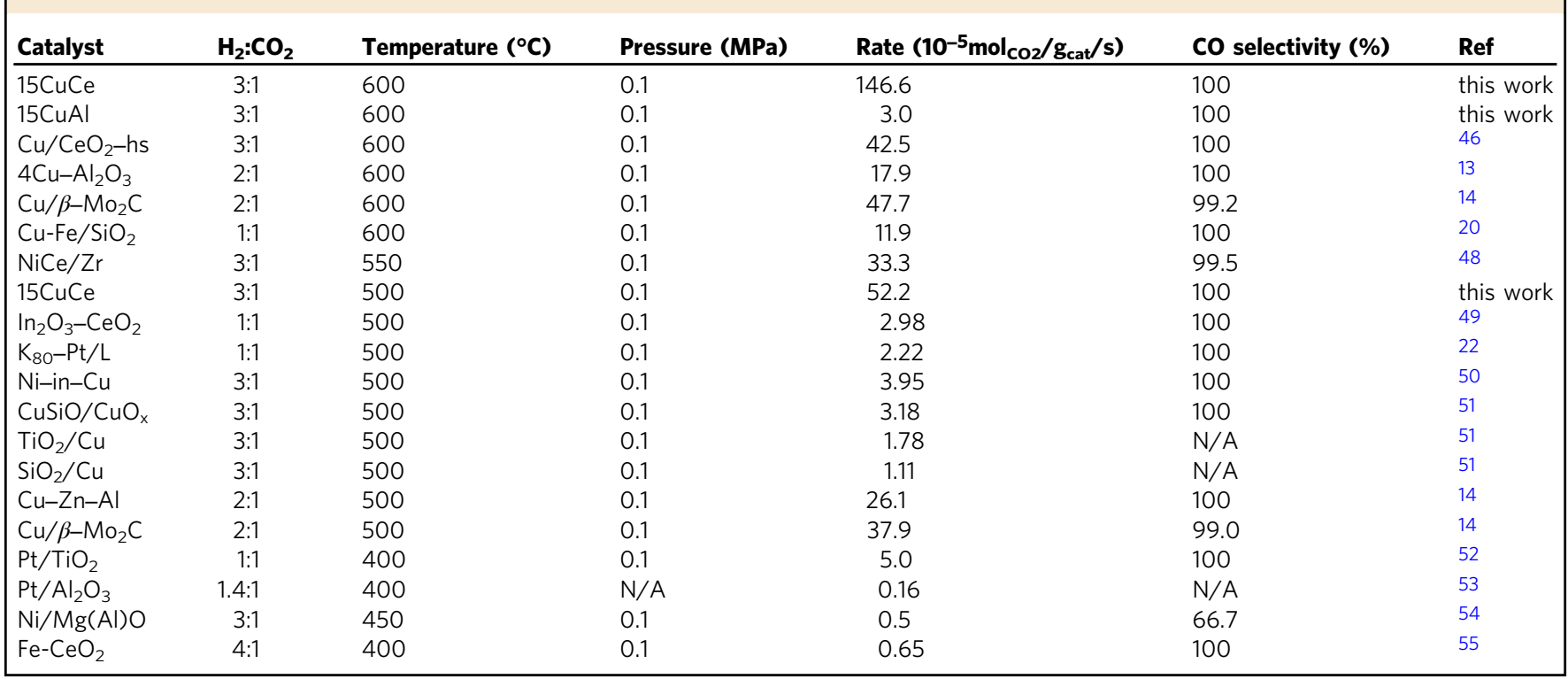

optimal $15 \mathrm{CuCe}$ catalyst achieved the combination of high activity and high stability.

Structural characterization of the copper-ceria catalysts. The catalytic performances of catalysts are closely related to the structure of the catalyst. The transmission electron microscopy (TEM) images of the fresh $15 \mathrm{CuCe}$ catalyst presented the regular rod-like structure with length ranging from about 50 to $200 \mathrm{~nm}$ (Supplementary Fig. 7a). The EDS mapping results (Supplementary Fig. 7b) suggested that copper species were well dispersed in the fresh $15 \mathrm{CuCe}$ catalyst. The catalysts with relative low copper loading exhibited the similar size and morphology as the 15CuCe catalyst (Supplementary Fig. 8). As for the fresh and used $25 \mathrm{CuCe}$ catalysts, a large number of isolated copper particles (tens to hundreds nanometers, labeled by circle in red) were observed (Supplementary Fig. 8h and k), which indicated that the optimized copper loading was around $15 \mathrm{wt} \%$. This phenomenon showed that it was crucial to load proper amount of copper on the ceria support. The addition of excess copper results in agglomeration and deactivation, while catalysts with low $\mathrm{Cu}$ concentration suffer from insufficient $\mathrm{Cu}$ active sites, ending up with poor catalytic performance. For the $15 \mathrm{CuCe}$ catalyst after $\mathrm{H}_{2}$ pretreatment, the high-angle annular dark-field (HAADF) images 


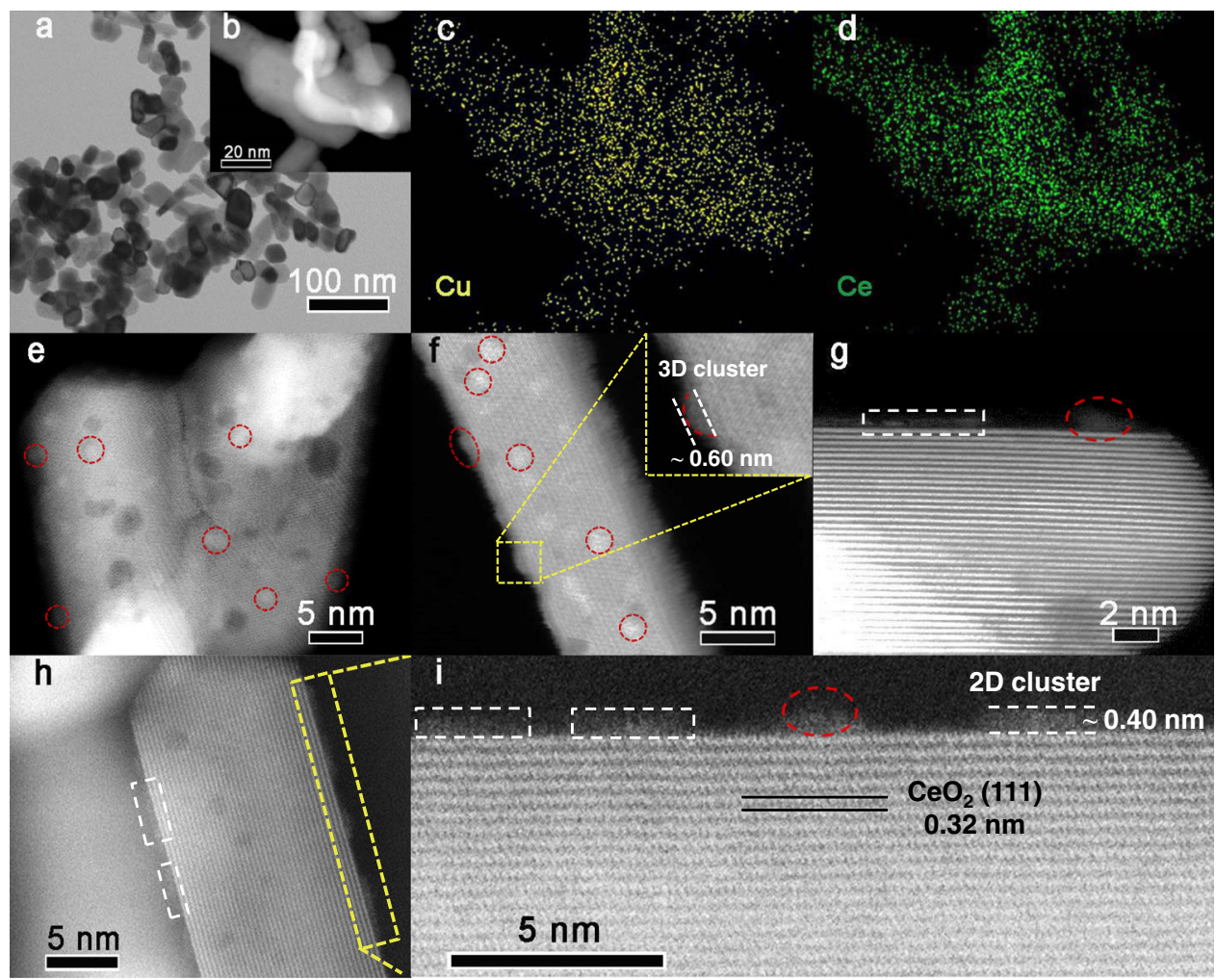

Fig. 2 Structure characterization of the $\mathbf{1 5 C u C e}$ catalyst after $\mathbf{7 0} \mathbf{h}$ stability test. a Transmission electron microscope (TEM) image; b-d Scanning transmission electron microscope (STEM) image and element mapping results; e-h High-angle annular dark-field (HAADF) STEM images; i Enlarged image of the highlighted region in (h).

(Supplementary Fig. 9) indicated that ceria nanorods could maintain the rod-like morphology, suggesting ceria nanorods have not undergone obvious sintering prior to the RWGS reaction. In addition, 2D layered and 3D hemisphere-shaped copper clusters could be clearly observed on the surface of $\mathrm{CeO}_{2}$ nanorods. The width of the $2 \mathrm{D}$ layered clusters ranged from $1 \mathrm{~nm}$ to $3.5 \mathrm{~nm}$, and the thickness was from about $0.2 \mathrm{~nm}$ to $0.5 \mathrm{~nm}$. The diameter of $3 \mathrm{D}$ clusters was around $2 \mathrm{~nm}$. Besides, as shown in Fig. 2a, compared to the used catalyst with slight sintering after temperature-dependent evaluation (Supplementary Fig. 8j), the $\mathrm{CeO}_{2}$ nanorods underwent more obvious sintering during the long-term reaction of $70 \mathrm{~h}$ at high temperature. However, the excellent activity and stability of the catalyst (Fig. 1a and d) meant that there might still be abundant active metal sites on the partially sintered ceria support. As shown in Fig. 2b-d and Supplementary Fig. 10, the EDS elemental mapping images demonstrated the high dispersion of copper, with $\mathrm{Cu}$ signal appearing uniformly on the surface of the partially sintered catalyst. And the HAADF images indicated on the surface of the partially sintered copper-ceria catalyst, copper also existed dominantly in the forms of 2D layered clusters and 3D hemisphere shaped clusters (Fig. 2e-i and Supplementary Fig. 11), similar to the activated samples. The average thickness of the layered clusters was about $0.4 \mathrm{~nm}$ (Fig. 2i), which was approximately consistent with a bilayer configuration of copper atoms ${ }^{25}$. The widths of the 2D layered clusters varied from $1.5 \mathrm{~nm}$ to $4 \mathrm{~nm}$. And the mean width and average thickness of the $3 \mathrm{D}$ clusters were $1.3 \mathrm{~nm}$ and $0.6 \mathrm{~nm}$, respectively.

Although many excellent reports have explored the structure of copper-ceria catalysts ${ }^{25,27}$, the structure of the copper-ceria catalyst, including the status of copper species and morphology of ceria, is almost unknown under harsh reaction conditions (at high temperature and with the reductive atmosphere), especially for the catalyst with relatively high copper loading. In order to explore the structure of the $15 \mathrm{CuCe}$ catalyst after a long enough reaction time, the measurement by an HAADF-STEM of the sample after $240 \mathrm{~h}$ RWGS reaction was performed. As shown in Fig. $3 \mathrm{a}, \mathrm{CeO}_{2}$ nanorods were still partially sintered, but not completely sintered, which indicated that $\mathrm{CeO}_{2}$ nanorods could not oversinter to cause the severe deactivation. And the EDS mapping images (Fig. 3b-d and Supplementary Fig. 12) suggested that the copper species were still highly dispersed on the partially sintered $\mathrm{CeO}_{2}$ support. As illustrated in Fig. 3e-i, even though the reaction time has been extended to $240 \mathrm{~h}, 2 \mathrm{D}$ and $3 \mathrm{D}$ copper clusters were anchored on the partially sintered $\mathrm{CeO}_{2}$ nanorods, which undoubtedly prevented the catalyst from being inactivated by the agglomeration of active copper species. According to the above experimental results, the structural evaluation of the $15 \mathrm{CuCe}$ catalyst during the long-term reaction could be shown in the Fig. 3j. Under the harsh reaction conditions, the ceria support sintered partially, but copper species were still anchored as clusters on the catalyst surface. However, for the reference $15 \mathrm{CuAl}$ catalyst, even though the $\mathrm{Al}_{2} \mathrm{O}_{3}$ support was very stable under high temperature, copper species have agglomerated significantly during the reaction, which caused severe deactivation in activity (Supplementary Fig. 13). And the $15 \mathrm{CuCe}$ catalyst prepared by the impregnation (IMP) method with poor dispersion of copper also exhibited much inferior activity (Supplementary Fig. 14).

In Table 2, the actual $\mathrm{Cu}$ content of the copper-ceria catalysts was similar to that of the theoretical value. And the $\mathrm{Cu} / \mathrm{CeO}_{2}$ catalysts exhibited similar specific BET surface areas $\left(80.1-88.2 \mathrm{~m}^{2} \cdot \mathrm{g}^{-1}\right)$ except the $15 \mathrm{CuAl}$ catalyst showed a larger value $154.7 \mathrm{~m}^{2} \cdot \mathrm{g}^{-1}$. X-ray diffraction (XRD) results (Supplementary Fig. 15) showed that fluorite $\mathrm{CeO}_{2}$ served as dominate phase for all the fresh and used catalysts except the $25 \mathrm{CuCe}$ catalyst. And from the XRD results 

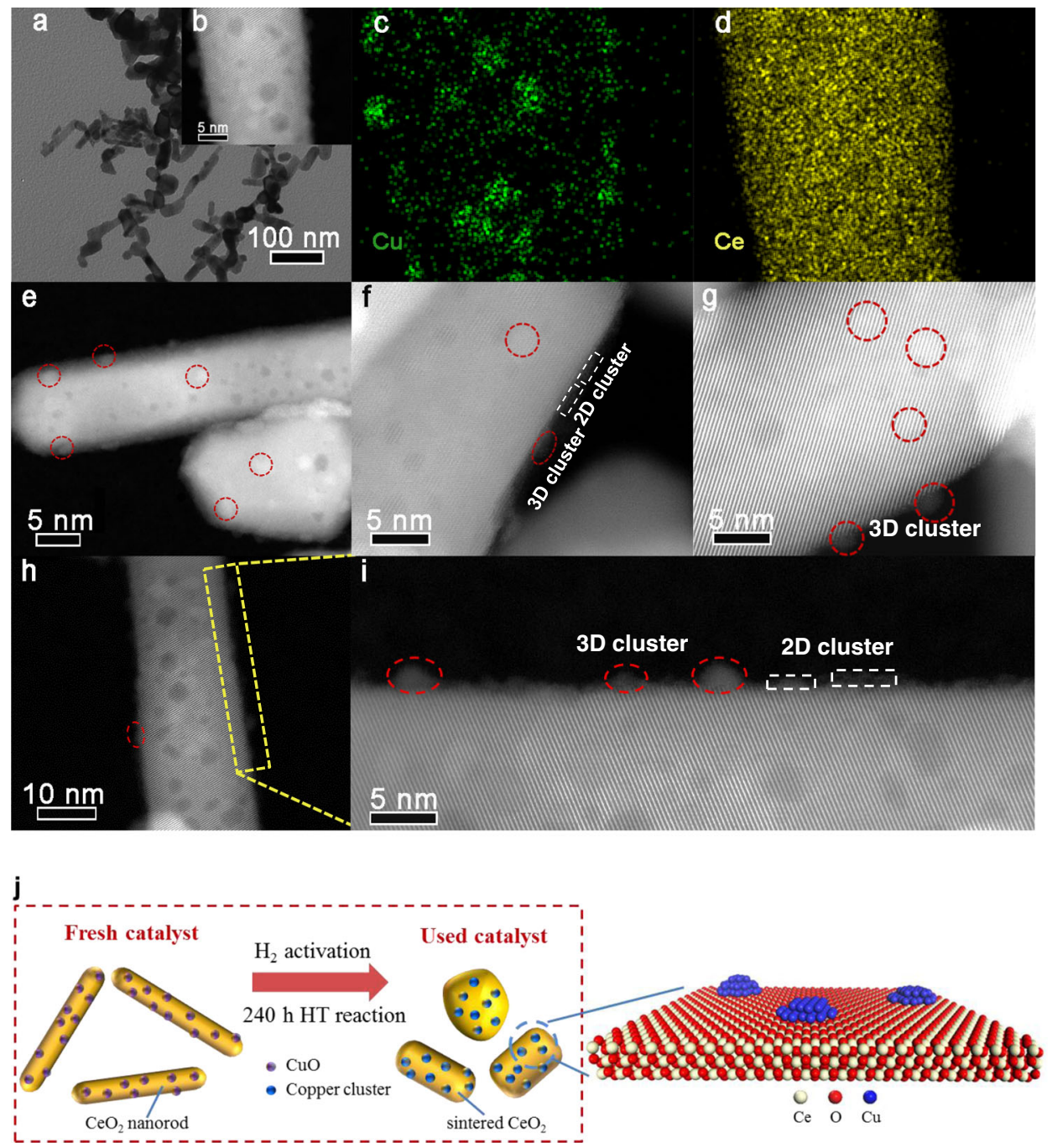

Fig. 3 Structure characterization of the $\mathbf{1 5 C u C e}$ catalyst after $\mathbf{2 4 0} \mathbf{h}$ stability test. a TEM image; b-d STEM images and element mapping results. $\mathbf{e}-\mathbf{h}$ HAADF-STEM images; $\mathbf{i}$ Enlarged image of the highlighted region in (h); $\mathbf{j}$ Scheme of structural evolution for the copper-ceria catalyst during long-term stability test.

\section{Table 2 Physicochemical properties of catalysts.}

\begin{tabular}{|c|c|c|c|c|}
\hline Catalyst & $\mathrm{Cu}(w \mathrm{w} . \%)^{\mathrm{a}}$ & $S_{\mathrm{BET}}\left(\mathrm{m}^{2} \cdot \mathrm{g}^{-1}\right)^{\mathrm{b}}$ & $\mathrm{H}_{2}\left(\mu \mathrm{mol} \cdot \mathrm{g}^{-1}\right)^{\mathrm{c}}$ & Integral $D / F_{2 g}$ signald $^{d}$ \\
\hline$\overline{1 \mathrm{CuCe}}$ & 0.8 & 86.2 & $\alpha_{430} \beta_{124}$ & ${ }^{\alpha} 0.11,{ }^{\beta} 0.16$ \\
\hline $5 \mathrm{CuCe}$ & 3.4 & 88.2 & $\alpha 1191, \beta 510$ & ${ }^{\alpha} 0.47, \beta_{0.67}$ \\
\hline $10 \mathrm{CuCe}$ & 9.7 & 83.9 & $\alpha_{2543,} \beta_{1352}$ & $\alpha_{0.60}, \beta 0.96$ \\
\hline $15 \mathrm{CuCe}$ & 15.2 & 83.3 & $\alpha 3791, \beta 1996$ & $\alpha 0.65, \beta 1.50$ \\
\hline $25 \mathrm{CuCe}$ & 26.5 & 80.1 & $\alpha 4647, \beta 3062$ & $\alpha 0.75, \beta 1.69$ \\
\hline 15CuAl & 16.1 & 154.7 & / 1 - n & / \\
\hline
\end{tabular}

aDetermined with ICP-OES

betermined with $\mathrm{N}_{2}$ adsorption.

cActual values of $\mathrm{H}_{2}$ consumption $(\alpha)$ and theoretic values of $\mathrm{H}_{2}$ consumption calculated according to $\mathrm{Cu}^{2+} \rightarrow \mathrm{Cu}^{0}(\beta)$

${ }^{\mathrm{d}} D / F_{2 g}$ internal ratio of fresh catalysts $(\alpha)$ and used catalysts $(\beta)$.

(Supplementary Fig. 13) of the fresh $15 \mathrm{CuCe}$ and used $15 \mathrm{CuCe}$ catalysts after $70 \mathrm{~h}$ stability test, it could be seen that copper species existed mainly in the form of $\mathrm{CuO}$ before the reaction and metallic $\mathrm{Cu}^{0}$ after the reaction. The tiny diffraction peak of $\mathrm{Cu}^{0}$ also suggested that copper could maintain very small size even after a long period of high-temperature reaction, which was also consistent with the results of STEM. The $\mathrm{Cu} 2 p$ X-ray photoelectron spectroscopy (XPS) spectra of the fresh, activated, and used $15 \mathrm{CuCe}$ catalyst were shown in Supplementary Fig. 16. The XPS peaks centered at 933.6 and $932.4 \mathrm{eV}$ were attributed to the $\mathrm{Cu} 2 p_{3 / 2}$ region; According to the previous reports, the peak centered at $933.6 \mathrm{eV}$ was attributed to the $\mathrm{Cu}^{2+}$ species, and $932.4 \mathrm{eV}$ was assigned to $\mathrm{Cu}^{+} / \mathrm{Cu}^{0}$ species ${ }^{30}$. It indicated that only $\mathrm{Cu}^{2+}$ was detected for the fresh $15 \mathrm{CuCe}$ catalyst, while for the activated and used $15 \mathrm{CuCe}$ sample, the $\mathrm{Cu}^{+} / \mathrm{Cu}^{0}$ species appeared. This result indicated that the surface $\mathrm{Cu}^{2+}$ species was reduced to $\mathrm{Cu}^{+}$or $\mathrm{Cu}^{0}$ in the activation process.

The interaction between the copper and ceria in the catalyst. The high dispersion of the copper species reflected the interaction between copper and ceria. For the fresh $\mathrm{Cu} / \mathrm{CeO}_{2}$ catalysts, such interaction can be confirmed by $\mathrm{H}_{2}$ temperature-programmed reduction $\left(\mathrm{H}_{2}-\mathrm{TPR}\right)^{8}$. As shown in supplementary Fig. 17a, the TPR profiles could be deconvoluted into three peaks. In the previous report ${ }^{31}$, the EXAFS data confirmed the existence of $\mathrm{Cu}$ $\mathrm{O}$ and $\mathrm{Cu}-\mathrm{Ce}$ binding in the $\mathrm{Cu} / \mathrm{CeO}_{2}-\mathrm{NR}$ catalyst, which was quite consistent with the reduction peaks of $\mathrm{CuO}_{x}$ clusters and the $\mathrm{Cu}-\left[\mathrm{O}_{x}\right]$-Ce structure. However, the experimental result in the Supplementary Fig. $17 \mathrm{~b}$ and other reports ${ }^{32}$ indicated that the $\mathrm{H}_{2}$-TPR pattern of pure $\mathrm{CuO}$ was not completely symmetric, which suggested that the reduction of $\mathrm{CuO}_{x}$ was not completed in one step, suggesting the $\mathrm{CuO}_{x}$ species were progressively reduced to $\mathrm{Cu}^{+}$and $\mathrm{Cu}^{0}$ species. Besides, the reduction peak of $\mathrm{CuO}$ 
a

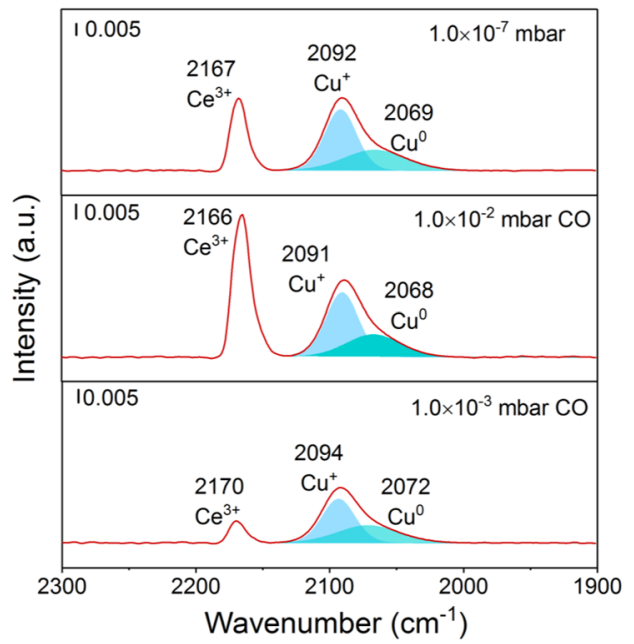

b

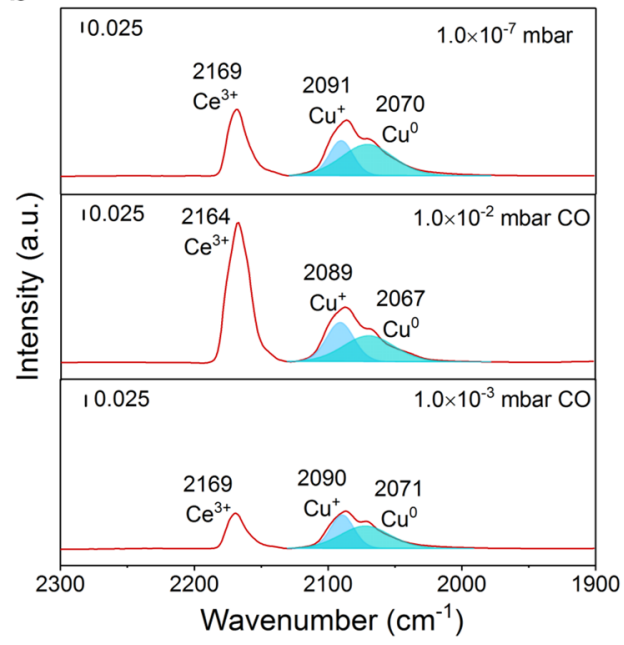

Fig. 4 The interaction between copper and ceria. a-b In situ infrared spectra recorded after exposing the $15 \mathrm{CuCe}$ catalyst to $\mathrm{CO}$ with different partially pressure at $-143^{\circ} \mathrm{C}$ after $\mathrm{H}_{2}$ pretreatment (a) and $70 \mathrm{~h}$ stability test at $600^{\circ} \mathrm{C}$ (b), respectively.

could not be deconvoluted into two symmetric peaks, indicated the reduction of $\mathrm{Cu}^{2+}$ to $\mathrm{Cu}^{+}$and the reduction of $\mathrm{Cu}^{+}$to $\mathrm{Cu}^{0}$ occurred simultaneously in a certain range of reduction temperature. Therefore, we speculated the reduction peaks of highly dispersed $\mathrm{CuO}_{x}$ clusters in copper-ceria catalysts were also not symmetric, and the $\alpha$ and $\beta$ peaks could not be attributed to the reduction of single species, but the progressively reduction of $\mathrm{CuO}_{x}$ species to $\mathrm{Cu}^{+}$and $\mathrm{Cu}^{0}$ species. Furthermore, the hightemperature sharp peak $\left(170-260^{\circ} \mathrm{C}\right)$ was due to the reduction of the strong interaction of $\mathrm{Cu}-\left[\mathrm{O}_{x}\right]-\mathrm{Ce}$ structure ${ }^{30}$. Comparing to the $\mathrm{H}_{2}$-TPR results of pure $\mathrm{CeO}_{2}$ and $\mathrm{CuO}$ (Supplementary Fig. $17 \mathrm{~b}$ ), the $\mathrm{CuO}-\mathrm{CeO}_{2}$ interaction enhanced the redox properties of these catalysts ${ }^{33}$. However, the reduction temperature of the reference $15 \mathrm{CuAl}$ catalyst was close to that of pure $\mathrm{CuO}$, which meant there was a very weak interaction between copper and alumina (Supplementary Fig. 18). With such weak interaction, copper were difficult to be stabilized on the $\mathrm{Al}_{2} \mathrm{O}_{3}$ support under the high-temperature reduction conditions, causing the severe deactivation of the $15 \mathrm{CuAl}$ catalyst.

In order to further explore the interaction between the interfacial copper and ceria in the $15 \mathrm{CuCe}$ catalyst after the $\mathrm{H}_{2}$ pretreatment and the stability test, the in situ infrared spectroscopy at the low temperature $\left(-143^{\circ} \mathrm{C}\right)$ was measured by using the $\mathrm{CO}$ as probe molecule. As shown in Fig. $4 \mathrm{a}$, three CO bands appeared after $1.0 \times 10^{-3}$ mbar CO was injected. The band at $2166-2170 \mathrm{~cm}^{-1}$ was assigned to $\mathrm{CO}$ adsorbed at the $\mathrm{Ce}^{3+}$ site $\mathrm{e}^{25}$. And the two bands at $2092 \mathrm{~cm}^{-1}$ and $2069 \mathrm{~cm}^{-1}$ were attributed to the $\mathrm{CO}$ adsorption on the $\mathrm{Cu}^{+}$and $\mathrm{Cu}^{0}$ sites ${ }^{34}$, respectively. The intensity of all CO bands increased with the increase of CO pressure, especially at the $\mathrm{Ce}^{3+}$ site. Then with the rising of the degree of vacuum to $1.0 \times 10^{-7}$ mbar, the rapid elimination of adsorbed $\mathrm{CO}$ at the $\mathrm{Ce}^{3+}$ was observed, which was related to the weak binding energy of $\mathrm{CO}-\mathrm{Ce}^{3+}$. The $\mathrm{CO}-\mathrm{Cu}^{+}$related infrared bands demonstrated that part of $\mathrm{Cu}^{+}$sites could not be reduced during the $\mathrm{H}_{2}$ activation process. Besides, as for the partially sintered $15 \mathrm{CuCe}$ sample after the stability test, there were also three bands appeared (Fig. 4b). The presence of the $\mathrm{Cu}^{+}$site and the $\mathrm{Ce}^{3+}$ site confirmed that the interaction between the positively charged copper atoms with eletrophilicity and the $\mathrm{Ce}^{3+}$ with nucleophilicity was not destroyed after long time treatment of reductive atmosphere at high temperature of $600{ }^{\circ} \mathrm{C}$. The $\mathrm{H}_{2}$-TPR result for the $15 \mathrm{CuCe}$ catalyst after the temperatureprogrammed surface reaction (TPSR) test also gave a reduction peak (Supplementary Fig. 19), which again suggested a part of copper species remain $\mathrm{Cu}^{\delta+}$ with electrophilicity during the reaction due to the interaction between copper and ceria ${ }^{32}$. Therefore, there was no doubt that the stable interaction between copper and ceria were present, which ensured the high dispersion and high stability of the active copper sites under harsh conditions.

Role of the surface oxygen vacancy in the catalysts. Due to the interaction between copper and ceria, the $\mathrm{Ce}^{4+}$ can be transformed to $\mathrm{Ce}^{3+}$, which is accompanied by the formation of oxygen vacancy $8,34-36$. It has been reported that oxygen vacancies commonly are recognized as the crucial active site to adsorb and dissociate $\mathrm{CO}_{2}{ }^{28,37}$, playing an important role in the $\mathrm{CO}_{2}$ reduction reaction. Luis $\mathrm{F}$. Bobadilla et al. demonstrated that the dissociation paths of $\mathrm{CO}_{2}$ on reductive and non-reductive supports were different, the oxygen vacancies on reductive supports could activate $\mathrm{CO}_{2}$ more efficiently ${ }^{38}$. However, $\mathrm{CO}_{2}$ is a stable molecule, whose dissociation rate is closely related to the number of oxygen vacancies ${ }^{39}$. In this work, ex situ and in situ Raman spectra were performed to characterize the oxygen vacancies of the catalysts. In ex situ Raman results of all fresh and used copper-ceria catalysts (Supplementary Fig. 20), besides the vibration mode $\left(F_{2 \mathrm{~g}}\right)$ of $\mathrm{CeO}_{2}$ fluorite-type structure at $\sim 454 \mathrm{~cm}^{-1}$, a broad $D$ band was also found ${ }^{8}$. The $D_{1}$ peak located at $\sim 543 \mathrm{~cm}^{-1}$ resulted from surface oxygen vacancy where $\mathrm{Ce}^{4+}$ was replaced by $\mathrm{Ce}^{3+}$. And the $D_{2}$ peak at $\sim 603 \mathrm{~cm}^{-1}$ was the intrinsic defect in ceria 40,41 . The relative integral intensity ratio of $D / F_{2 g}$ reflected the concentration of oxygen vacancies in each catalyst ${ }^{3,8,42,43}$. As illustrated in Supplementary Figure 20, the relative strength of the $D$ band gradually increased with the increase of copper loading which meant that copper could promote the creation of oxygen vacancies. And the oxygen vacancy concentration of the used catalysts was higher (Table 2), indicating that more oxygen vacancies were created during the pretreatment and reaction process. The $\mathrm{H}_{2}-\mathrm{TPR}$ results of all the $\mathrm{Cu} / \mathrm{CeO}_{2}$ catalysts also reflected that the amounts of hydrogen consumption of these catalysts were bigger than the theoretical values based on the complete reduction of $\mathrm{Cu}^{2+}$ to $\mathrm{Cu}^{0}$ (Table 2). This was due to the reduction of surface oxygen of the ceria at relatively low temperature by the aids of highly dispersed copper clusters. The more practical $\mathrm{H}_{2}$ consumption exceeded the theoretical value, the more 
a
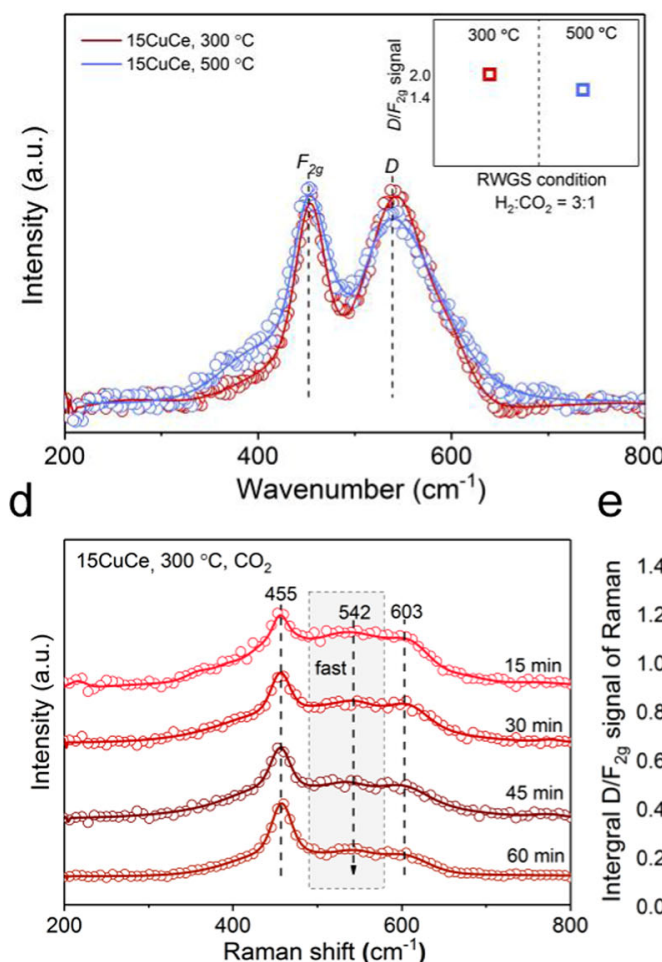

b

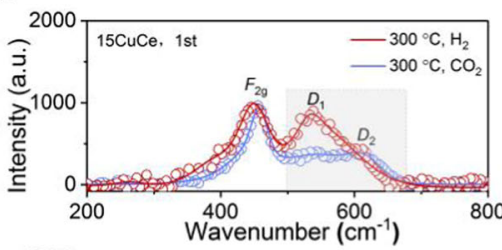

C
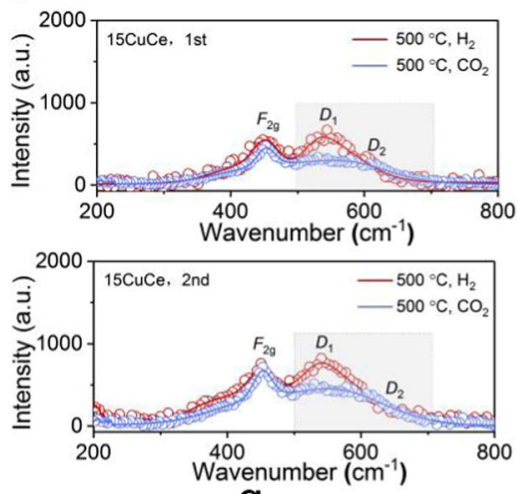

g
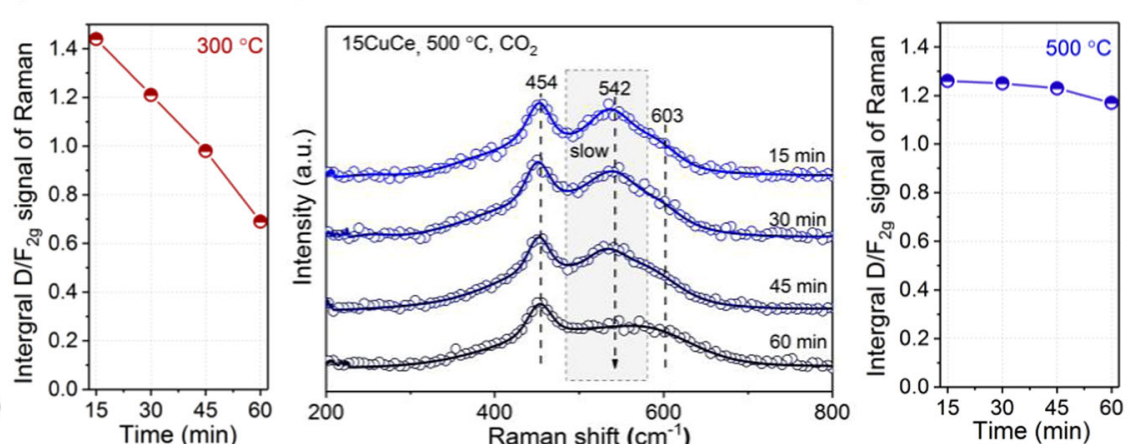

Fig. 5 Examination of oxygen vacancies in the copper-ceria catalysts. a In situ Raman under the RWGS reaction conditions for the $15 \mathrm{CuCe}$ catalyst; $\mathbf{b}-\mathbf{c}$ In situ Raman of the $15 \mathrm{CuCe}$ catalyst with $\mathrm{H}_{2} / \mathrm{CO}_{2}$ switching under $300^{\circ} \mathrm{C}$ and $500^{\circ} \mathrm{C}$, respectively; d-e The in situ Raman spectra over the $15 \mathrm{CuCe}$ catalyst under $\mathrm{CO}_{2}$ flow at $300^{\circ} \mathrm{C}$ and the variation of $\mathrm{I}_{\mathrm{D}} / \mathrm{I}_{\mathrm{F} 2 \mathrm{~g}}$ intensity ratio with time; $\mathbf{f}-\mathbf{g}$ The in situ Raman spectra over the $15 \mathrm{CuCe}$ catalyst under $\mathrm{CO}{ }_{2}$ flow at $500^{\circ} \mathrm{C}$ and the variation of $I_{D} / I_{F 2 g}$ intensity ratio with time.

oxygen vacancies were formed ${ }^{44}$. And for the $\mathrm{Cu} / \mathrm{CeO}_{2}$ catalysts after reaction, more oxygen vacancies were produced on the surface by the effect of the reductive reaction gas $\left(69 \% \mathrm{H}_{2} / 23 \%\right.$ $\mathrm{CO}_{2} / 8 \% \mathrm{~N}_{2}$ ).

To explore the role of oxygen vacancy in the actual reaction process further, the in situ Raman under reaction condition at $300{ }^{\circ} \mathrm{C}$ and $500{ }^{\circ} \mathrm{C}$ were measured and the results were showed in Fig. $5 \mathrm{a}$. The $15 \mathrm{CuCe}$ catalyst showed a strong peak centered at $543 \mathrm{~cm}^{-1}$, which was assigned as surface oxygen vacancies. Compared to the fresh $15 \mathrm{CuCe}$ catalyst, the $D_{1}$ band was even pronounced than $F_{2 \mathrm{~g}}$ peak during the reaction process, which meant that abundant surface oxygen vacancies were in situ generated during the reaction process. For the $5 \mathrm{CuCe}$ catalyst, the $D_{1}$ band was also obvious, which meant surface oxygen vacancies were ubiquitous in the reaction process for $\mathrm{Cu} / \mathrm{CeO}_{2}$ catalysts in this work (Supplementary Fig. 21). And as exhibited by the illustrations in Fig. 4a and Supplementary Fig. 21, the in situ Raman tests reflected that the copper-ceria catalyst contained similar concentrations of oxygen vacancies at $300^{\circ} \mathrm{C}$ and $500^{\circ} \mathrm{C}$. The small difference in the concentration of the oxygen vacancy could be considered within the error range. Besides, for the pure $\mathrm{CeO}_{2}$ support (Supplementary Fig. 22), the intensity of the $D$ peak was very weak in the reaction atmosphere, which again demonstrated that the addition of copper could create more oxygen vacancies on the surface of ceria.

In order to explore the relationship between the activation of reactant molecules $\left(\mathrm{H}_{2}\right.$ and $\left.\mathrm{CO}_{2}\right)$ and the oxygen vacancy, the in situ Raman spectra of the $15 \mathrm{CuCe}$ catalyst with $\mathrm{CO}_{2} / \mathrm{H}_{2}$ switch under $300^{\circ} \mathrm{C}$ and $500{ }^{\circ} \mathrm{C}$ were also measured. As shown in the Fig. $5 b$ and c, the Raman spectra of the $15 \mathrm{CuCe}$ catalyst after $\mathrm{H}_{2}$ treatment showed a strong characteristic peak of oxygen surface vacancy centered at $543 \mathrm{~cm}^{-1}$. When $\mathrm{CO}_{2}$ was filled in, the intensity of $D_{1}$ peak diminished, which meant that $\mathrm{CO}_{2}$ adsorbed on the surface oxygen vacancies and occupied them. However, the stable $\mathrm{D}_{2}$ peak suggested that $\mathrm{CO}_{2}$ adsorption almost has little effect on the intrinsic defects. This experimental phenomenon directly confirmed that the surface oxygen vacancy was involved in this reaction. The second cycle of in situ Raman measurement also gave the same conclusion that surface oxygen vacancies were created by $\mathrm{H}_{2}$, and consumed by $\mathrm{CO}_{2}$. This in situ Raman result indicated that the surface oxygen vacancies could be consumed and regenerated as the reaction progress, allowing for the existence of lots of surface oxygen vacancies on the catalyst surface which could promote the high activity and stability. Besides, the relationship between the concentration of oxygen vacancy and $\mathrm{CO}_{2}$ treatment time at $300^{\circ} \mathrm{C}$ and $500^{\circ} \mathrm{C}$ was also explored. As shown in the Fig. $5 \mathrm{~d}-\mathrm{g}$, the decrease rate of oxygen vacancy at $300^{\circ} \mathrm{C}$ was significantly faster than that at $500^{\circ} \mathrm{C}$. Combined with the results of the $\mathrm{CO}_{2}$-TPD in Supplementary Fig. 23, the adsorption of $\mathrm{CO}_{2}$ became more and more difficult with the increase of temperature. Therefore, it was easier for $\mathrm{CO}_{2}$ to adsorb on oxygen vacancies at $300^{\circ} \mathrm{C}$ compared to $500^{\circ} \mathrm{C}$. Besides, the effects of $\mathrm{H}_{2}$ and $\mathrm{CO}_{2}$ concentrations on the oxygen vacancy have also been investigated. As shown in Supplementary Fig. 24, the addition of $\mathrm{CO}_{2}$ could reduce the amount of oxygen vacancies. However, further increasing the concentration of $\mathrm{CO}_{2}$ did not significantly reduce the concentration of oxygen vacancies, which suggested that the rate. which $\mathrm{CO}_{2}$ consume oxygen vacancies was much slower than the rate of which $\mathrm{H}_{2}$ produced oxygen vacancies. The rapid formation of oxygen vacancies also meant the $15 \mathrm{CuCe}$ catalyst with dispersed copper clusters has a strong ability to dissociate $\mathrm{H}_{2}$.

Meanwhile, as illustrated in Supplementary Fig. 25, the reaction orders of $\mathrm{CO}_{2}$ for the $15 \mathrm{CuCe}$ and $5 \mathrm{CuCe}$ catalysts 

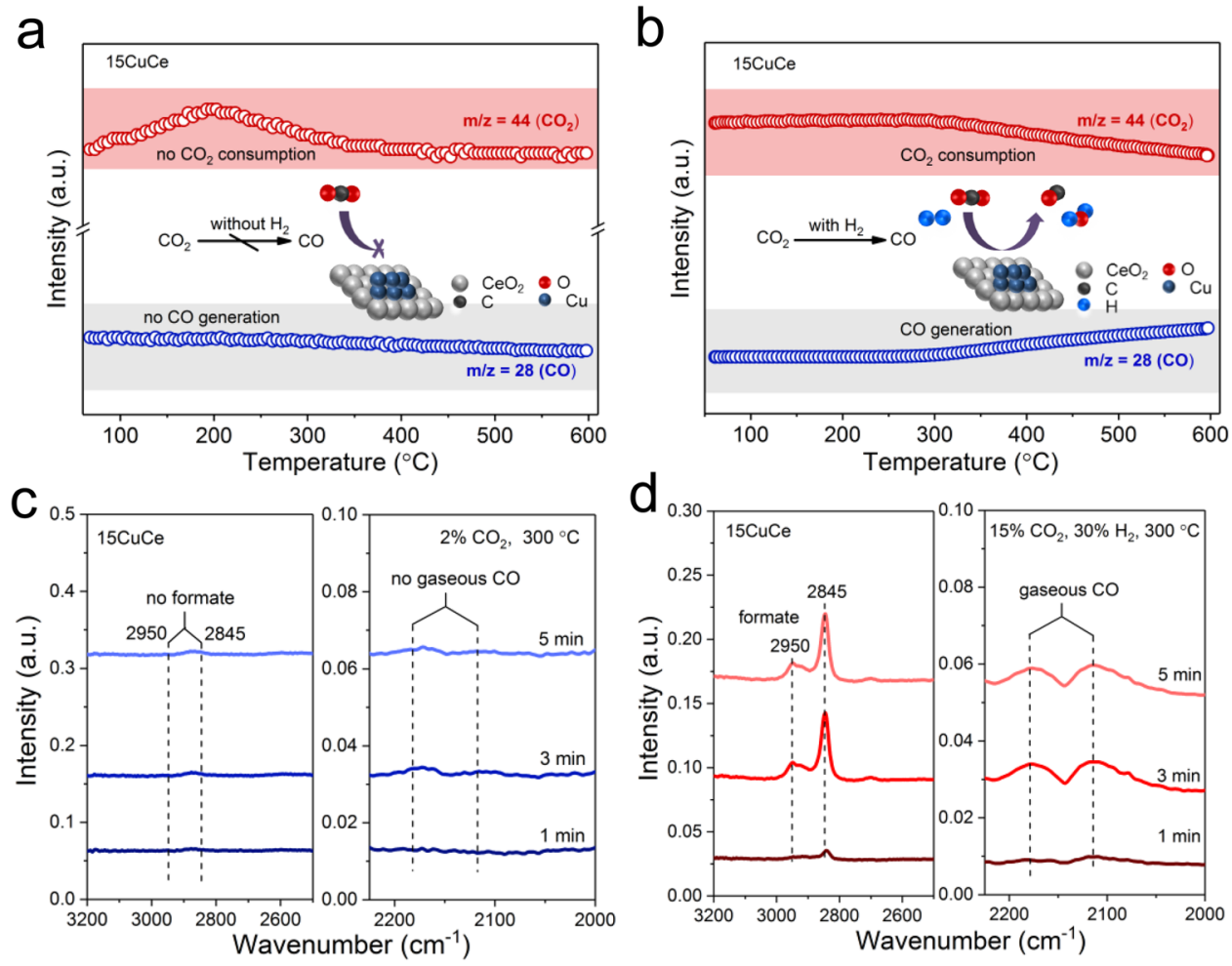

Fig. 6 RWGS mechanism and reactive intermediates study of the $\mathbf{1 5 C u C e}$ catalyst. a The $\mathrm{CO}_{2}$ dissociation experiment of the $15 \mathrm{CuCe}$ catalyst; $\mathbf{b}$ TPSR results of the $15 \mathrm{CuCe}$ catalyst; c-d In situ diffused reflectance infrared Fourier transform spectroscopy (DRIFTS) spectra of $15 \mathrm{CuCe}$ catalyst during $\mathrm{CO}_{2}$ treatment and reaction conditions at $300^{\circ} \mathrm{C}$, respectively.

were 0.25 and 0.52 , respectively. And the reaction orders of $\mathrm{H}_{2}$ over the $15 \mathrm{CuCe}$ and $5 \mathrm{CuCe}$ catalysts were 0.25 and 0.3 , respectively. The lower apparent reaction orders of $\mathrm{CO}_{2}$ and $\mathrm{H}_{2}$ on the $15 \mathrm{CuCe}$ catalyst compared to the $5 \mathrm{CuCe}$ sample reflected the reaction rate on the $15 \mathrm{CuCe}$ catalyst was less dependent on the concentrations of $\mathrm{CO}_{2}$ and $\mathrm{H}_{2}$, which might suggested $\mathrm{CO}_{2}$ and $\mathrm{H}_{2}$ were relatively easily adsorbed on the $15 \mathrm{CuCe}$ catalyst with more oxygen vacancies and copper sites.

Reaction mechanism study. The mechanisms of the RWGS reaction have been classified into two categories, redox mechanism. and associative mechanism ${ }^{19}$. Whether the dissociated $\mathrm{H}$ species involve in the formation of reactive intermediates (such as formate) is the key to distinguish these two mechanisms $\mathrm{s}^{45}$. In this work, the dissociation experiment of $\mathrm{CO}_{2}$ was performed to probe the reaction pathway. After the catalyst pretreated by $\mathrm{H}_{2} / \mathrm{Ar}$ at $600^{\circ} \mathrm{C}$ for $1 \mathrm{~h}$, the $\mathrm{CO}_{2} / \mathrm{Ar}$ mixed gas was introduced into the reactor at room temperature. As shown in Fig. 6a, there was no consumption of $\mathrm{CO}_{2}$ except for a part of the desorbed $\mathrm{CO}_{2}$ during the adsorption process. Meanwhile, there was no generation of $\mathrm{CO}$ could be found. The above experimental results indicated that it was difficult for $\mathrm{CO}_{2}$ itself to be directly dissociated to form $\mathrm{CO}$ by the $15 \mathrm{CuCe}$ catalyst. In Fig. 6 b, the TPSR result illustrated that $\mathrm{CO}_{2}$ signal gradually decreased and $\mathrm{CO}$ signal gradually increased from $\sim 300^{\circ} \mathrm{C}$, suggesting $\mathrm{CO}_{2}$ was converted into $\mathrm{CO}$ with the assistance of $\mathrm{H}_{2}$. Thus, combing the results of $\mathrm{CO}_{2}$ dissociation experiment and TPSR, it could be concluded that $\mathrm{CO}_{2}$ activation may processed via an associative intermediate pathway.

To further explore the active intermediates, the in situ diffused reflectance infrared Fourier transform spectroscopy (DRIFTS) was carried out. As shown in the Fig. 6c and Supplementary Fig. 26a, after the injection of $\mathrm{CO}_{2}$, only carbonate signal appeared and no CO gas signal was generated, which indicated carbonate was hard to dissociate directly into CO. However, as shown in Fig. 6d and Supplementary Fig. 26b, after the injection of $\mathrm{CO}_{2}$ and $\mathrm{H}_{2}$ over the activated $15 \mathrm{CuCe}$ catalyst, in addition to the carbonate signal, the $\mathrm{C}=\mathrm{O}$ vibration peak of formate at $1373 \mathrm{~cm}^{-1}$ and the typical C-H stretch vibration peaks of formate at $2949 \mathrm{~cm}^{-1}$ and $2845 \mathrm{~cm}^{-1}$ were observed ${ }^{46,47}$. Simultaneously, the broadband, which was attributed to the gaseous $\mathrm{CO}$ at $2000-2200 \mathrm{~cm}^{-1}$ has been detected as the increasing of the formate signal.

Calculations based on density functional theory (DFT) were also performed. The adsorption characteristics of $\mathrm{CO}_{2}$ suggested that the presence of $\mathrm{Cu}$ atoms assured that the decreasing entropy step could occur, shown as Fig. 7a, b and Supplementary Table 2. Notwithstanding the situation of oxygen vacancy affected the binding force, the energy could be reduced more than one electron-volt under the bonding interaction between $\mathrm{Cu}$ and $\mathrm{CO}_{2}$. And in the presence of $\mathrm{H}_{2}, \mathrm{Cu}$ atoms captured $\mathrm{H}_{2}$ molecule and broken $\mathrm{H}-\mathrm{H}$ bond, then transferred $\mathrm{H}$ atom to $\mathrm{CO}_{2}$, shown as Fig. 7c. Formate structures formed accompanying the formation of $\mathrm{C}-\mathrm{H}$ bond, and these structures exhibited in the intermediate IMA3, IMA3-I, IMA4, and IMA4-I. The heat liberation declared that the formate formation was a thermodynamic feasible elementary reaction. The subsequent hydrogen-migration step $(\Delta E=1.587 \mathrm{eV})$ was the thermodynamically limiting step, and this might be the reason that formate signals were detected by DRIFTS. Carboxylic intermediates, IMA3-II and IMA4-II, were involved in the mechanism at the same time. Different from the formate intermediates, one step was absent from the carboxylic path, i.e., IMA4-II produced IMA6 directly. Based on the above experimental results and DFT calculations, we could further infer that the associative mechanism was involved in this reaction and the surface formate and carboxylic species might be the important reactive intermediates. The synergistic catalytic effect between copper clusters and oxygen vacancies copper clusters promoted 


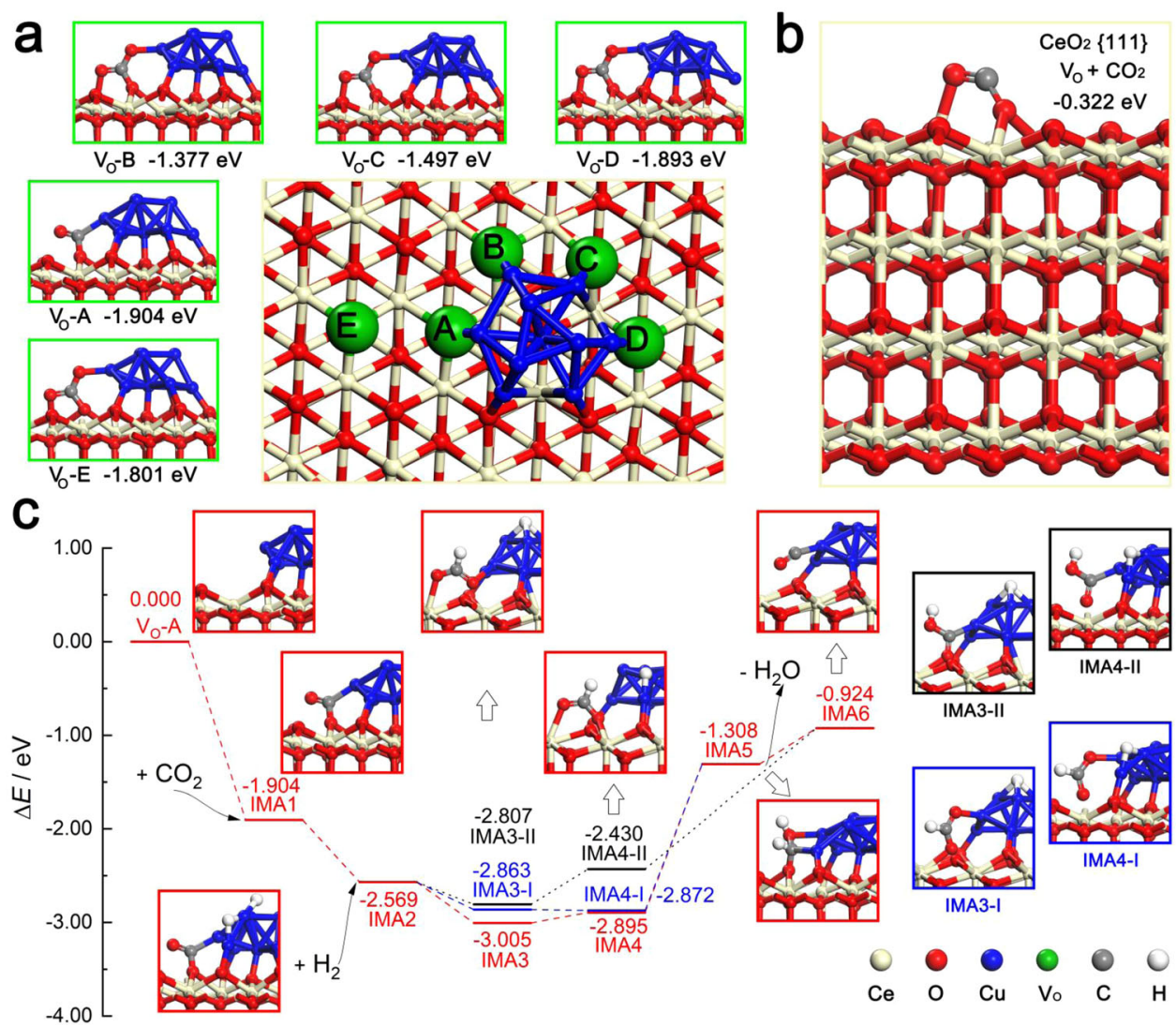

Fig. 7 The proposed reaction pathways for the RWGS reaction on the copper-ceria catalyst. a Chemisorption of $\mathrm{CO}_{2}$ on the $10 \mathrm{Cu} / \mathrm{CeO} \mathrm{O}_{2}\{111\}$ surface. Five oxygen vacancies, named after $\mathrm{V}_{\mathrm{O}}-\mathrm{A}$ to $\mathrm{V}_{\mathrm{O}}-\mathrm{E}$, were made comparisons, and the selected $\mathrm{CO}_{2}$ was located close to $\mathrm{V}_{\mathrm{O}}-\mathrm{A}$; $\mathbf{b}$ The adsorption energy that $\mathrm{CO}_{2}$ was bound to $\mathrm{V}_{\mathrm{O}}$ on the $\mathrm{CeO}_{2}\{111\}$ surface was obviously weaker than those of $\mathrm{Cu}$ dropped ceria sites; $\mathbf{c}$ RWGS reaction mechanism occurred in the $\mathrm{V}_{\mathrm{O}} \mathrm{-A}$. The red, blue, and black lines indicated different reaction paths, and the structural diagrams with the red, blue or black stroke corresponded to the reaction paths, respectively.

the adsorption of $\mathrm{CO}_{2}$ and the formation of active intermediates. The sufficient copper clusters and abundant oxygen vacancies in the $15 \mathrm{CuCe}$ catalyst undoubtedly created more metal clusteroxygen vacancy active interfaces.

\section{Discussion}

For high-temperature catalytic reactions, the development of catalysts with both high activity and excellent stability has always been difficult. In this work, highly dispersed active copper clusters with high loading (15 wt.\%) were stably constructed on the partially sintered copper-ceria catalyst during the real reaction process. The optimal $15 \mathrm{CuCe}$ catalyst exhibited excellent catalytic performance to catalyze the RWGS reaction at high operating temperature, which surpassed almost all the reported non-noble metal catalysts and costly noble metal catalysts. The harsh reaction conditions of high temperature and reductive atmosphere caused the ceria support sintered partially, while the interaction between copper and ceria maintained well. The unexpected stable interaction ensured the copper species to maintain stable in the forms of 2D layered clusters and 3D hemisphere-shaped clusters on the partially sintered ceria support. Besides, abundant surface oxygen vacancies were in situ generated and consumed circularly during the reaction process, forming the synergistic catalytic effect with copper cluster to promote the activation of $\mathrm{CO}_{2}$ and the formation of active intermediates. The unmatched activity and solid stability of this catalyst show great potentials in the practical applications. And the reveal of the structure-function relationship of the catalyst with sintered configuration also provides a reference for other systems.

\section{Methods}

Preparation of copper-ceria catalysts. The copper-ceria catalyst was prepared by the deposition-precipitation (DP) method. Firstly, the ceria support $(0.50 \mathrm{~g})$ was dispersed in $30 \mathrm{~mL}$ high purity water under continuous stirring. Next, different amounts of copper precursor, $\mathrm{Cu}\left(\mathrm{NO}_{3}\right) \cdot 3 \mathrm{H}_{2} \mathrm{O}$, were dissolved in $12.5 \mathrm{~mL}$ of high pure water, and then added into the above $\mathrm{CeO}_{2} / \mathrm{H}_{2} \mathrm{O}$ suspension dropwise. During the process of instilling, the $\mathrm{pH}$ value of the solution was controlled to ca. 9 by adding $\mathrm{Na}_{2} \mathrm{CO}_{3}$ solution $\left(0.50 \mathrm{~mol} \cdot \mathrm{L}^{-1}\right)$. The obtained precipitates were further aged at room temperature for $1 \mathrm{~h}$ before filtration, followed by washing with high pure water $(1 \mathrm{~L})$ at room temperature. The resulting material was dried in air at $75^{\circ} \mathrm{C}$ overnight and then calcined in still air at $600^{\circ} \mathrm{C}$ for $4 \mathrm{~h}$ (heating rate: $2^{\circ} \mathrm{C} /$ $\mathrm{min})$. The copper-ceria samples synthesized in this work were donated as $x \mathrm{CuCe}$ $(x=1,5,10,15$ and 25), where $x$ is the copper content in weight percent $(x=[\mathrm{Cu} /$ $\mathrm{CeO}_{2}$ ]wt $\left.\times 100 \%\right)$. The reference copper-ceria catalyst was prepared using the impregnation (IMP) method. $0.5 \mathrm{~g}$ of $\mathrm{CeO}_{2}$ support was dispersed in deionized water by stirring. Then the suitable amount of copper nitride was added into the slurry. The obtained mixture was dried at $90^{\circ} \mathrm{C}$ using an oil bath under stirring. The resulting material was calcined in still air at $600^{\circ} \mathrm{C}$ for $4 \mathrm{~h}$ (heating rate: $2^{\circ} \mathrm{C} /$ $\mathrm{min})$. The reference copper-ceria sample was donated as $15 \mathrm{CuCe}-\mathrm{IMP}$.

Transmission electron microscopy (TEM). Transmission electron microscopy (TEM) was undertaken by JEM-2100F (JEOL) instrument operating at $200 \mathrm{kV}$. The samples were dispersed in ethanol by ultrasonic and dropped on the carbon-coated $\mathrm{Cu}$ grid before test. The images of high-resolution TEM (HR-TEM) were obtained by using a JEOL JEM-2800 instrument with an acceleration voltage of $200 \mathrm{kV}$. The element mapping results and EDS analysis were acquired from the same machine under STEM mode. The High-angle annular dark-field scanning transmission electron microscopy (HAADF-STEM) images were obtained on a Thermo Scientific Themis $\mathrm{Z}$ microscope equipped with a probe-forming spherical-aberration corrector.

Raman test. All the ex situ and in situ Raman spectra were acquired by using a Raman microscope system (HORIBA JY) with laser excitation at $633 \mathrm{~nm}$. The integration times of ex situ and in situ Raman spectra were 1 min and 5 min, respectively. 
In situ infrared spectroscopy in the transmission mode. The infrared measurements were conducted in a UHV apparatus combining a FTIR spectrometer (Bruker Vertex $70 \mathrm{v}$ ) with a multi-chamber UHV syetem. The sample was pretreated with $\mathrm{H}_{2}$ or reaction gas at $873 \mathrm{~K}$ for $30 \mathrm{~min}$, and then exposed to CO with desired pressure at $130 \mathrm{~K}$.

Catalytic tests and kinetics measurement. The catalytic performance evaluation was tested in a fixed-bed flow reactor under a gas atmosphere of $23 \% \mathrm{CO}_{2} / 69 \% \mathrm{H}_{2} /$ $\mathrm{N}_{2}\left(66.7 \mathrm{~mL} \cdot \mathrm{min}^{-1}\right.$, Deyang Gas Company, Jinan) at 1 bar total pressure. Before the activity test, $10 \mathrm{mg}$ catalysts (40-60 mesh) diluted with $90 \mathrm{mg}$ inert $\mathrm{SiO}_{2}$ were activated by $5 \% \mathrm{H}_{2} / \mathrm{Ar}$ at $60{ }^{\circ} \mathrm{C}$ for $60 \mathrm{~min}$ followed by switching to the feed gas for testing. The test temperature ranges from $300^{\circ} \mathrm{C}$ to $600^{\circ} \mathrm{C}$. And before the analysis of gas products, the RWGS reaction needs to stabilize for $60 \mathrm{~min}$ at each test temperature. The gas products were analyzed by using an on-line gas chromatograph equipped with a thermal conductivity detector (TCD). $\mathrm{CO}_{2}$ conversion and $\mathrm{CO}$ selectivity were calculated using the following equations:

$$
\begin{aligned}
X_{\mathrm{CO}_{2}} & =\frac{n_{\mathrm{CO}_{2}}^{\text {in }}-n_{\mathrm{CO}_{2}}^{\text {out }}}{n_{\mathrm{CO}_{2}}^{\text {in }}} \times 100 \\
S_{\mathrm{CO}} & =\frac{n_{\mathrm{CO}}^{\text {out }}}{n_{\mathrm{CO}+}^{\text {out }} n_{\mathrm{CH}_{4}}^{\text {out }}} \times 100
\end{aligned}
$$

where $n_{\mathrm{CO}_{2}}^{\text {in }}$ is the concentration of $\mathrm{CO}_{2}$ in the reaction stream, and $n_{\mathrm{CO}_{2}}^{\text {out }}, n_{\mathrm{CO}}^{\text {out }}, n_{\mathrm{CH}_{4}}^{\text {out }}$ are the concentrations of $\mathrm{CO}, \mathrm{CO}_{2}, \mathrm{CH}_{4}$ in the outlet. The $\mathrm{CO}_{2}$ thermodynamic equilibrium conversion was calculated from HSC chemistry software version 6.0. The ratio of $\mathrm{H}_{2}: \mathrm{CO}_{2}$ in the initial state was 3:1, and the products including $\mathrm{CO}$, $\mathrm{H}_{2} \mathrm{O}$ and $\mathrm{CH}_{4}$ were taken into account in the calculation process. For all catalysts, the $E_{\mathrm{a}}$ was measured by using the same reactor for catalytic performance above. Appropriate amount of catalysts diluted with inlet $\mathrm{SiO}_{2}$ were used in the kinetics experiments. And in order to obtain accurate kinetics data, the catalysts need to be first treated with reactive gas for an hour at $600^{\circ} \mathrm{C}$. During the kinetic test, the $\mathrm{CO}_{2}$ conversion remained between $5 \%$ and $15 \%$ by changing gas flow rate. The reaction orders of $\mathrm{CO}_{2}$ and $\mathrm{H}_{2}$ for the catalysts were measured under $500^{\circ} \mathrm{C}$. The RWGS activity was recorded while the concentration of $\mathrm{CO}_{2}$ or $\mathrm{H}_{2}$ in the reaction gas was varied on purpose.

\section{Data availability}

The main data supporting the findings of this study are available within the article and its Supplementary information. All other relevant source data are available from the corresponding author upon reasonable request. Source data are provided with this paper.

Received: 9 June 2021; Accepted: 3 January 2022;

Published online: 14 February 2022

\section{References}

1. Zhang, $\mathrm{X}$. et al. A stable low-temperature $\mathrm{H}_{2}$-production catalyst by crowding Pt on a-MoC. Nature 589, 396-401 (2021).

2. Cargnello, M. et al. Control of metal nanocrystal size reveals metal-support interface role for ceria catalysts. Science 341, 771-773 (2013).

3. Fu, X. et al. Direct Identification of Active Surface Species for the Water-Gas Shift Reaction on a Gold-Ceria Catalyst. J. Am. Chem. Soc. 141, 4613-4623 (2019).

4. Zhang, Z. et al. Intrinsically Active Surface in a $\mathrm{Pt} / \gamma-\mathrm{Mo}_{2} \mathrm{~N}$ Catalyst for the Water-Gas Shift Reaction: Molybdenum Nitride or Molybdenum Oxide? J. Am. Chem. Soc. 142, 13362-13371 (2020).

5. Qiao, B. et al. Single-atom catalysis of CO oxidation using Pt1/FeOx. Nat. Chem. 3, 634-641 (2011)

6. Liu, X. et al. Activation of subnanometric $\mathrm{Pt}$ on $\mathrm{Cu}$-modified $\mathrm{CeO}_{2}$ via redoxcoupled atomic layer deposition for CO oxidation. Nat. Commun. 11, 4240 (2020).

7. Chen, C. S., Lin, J. H., You, J. H. \& Chen, C. R. Properties of $\mathrm{Cu}(\text { thd })_{2}$ as a Precursor to Prepare $\mathrm{Cu} / \mathrm{SiO}_{2}$ Catalyst Using the Atomic Layer Epitaxy Technique. J. Am. Chem. Soc. 128, 15950-15951 (2006).

8. Yan, H. et al. Construction of stabilized bulk-nano interfaces for highly promoted inverse $\mathrm{CeO}_{2} / \mathrm{Cu}$ catalyst. Nat. Commun. 10, 3470 (2019).

9. Campbell, C. T., Parker, S. C. \& Starr, D. E. The effect of size-dependent nanoparticle energetics on catalyst sintering. Science 298, 811-814 (2002).

10. Dai, Y., Lu, P., Cao, Z., Campbell, C. T. \& Xia, Y. The physical chemistry and materials science behind sinter-resistant catalysts. Chem. Soc. Rev. 47, 4314-4331 (2018).

11. Nelson, N. C., Chen, L., Meira, D., Kovarik, L. \& Szanyi, J. In Situ Dispersion of Palladium on $\mathrm{TiO}_{2}$ During Reverse Water-Gas Shift Reaction: Formation of Atomically Dispersed Palladium. Angew. Chem. Int. Ed. 59, 17657-17663 (2020).
12. Juneau, M. et al. Assessing the viability of $\mathrm{K}-\mathrm{Mo}_{2} \mathrm{C}$ for reverse water-gas shift scale-up: molecular to laboratory to pilot scale. Energ. Environ. Sci. 13, 2524-2539 (2020)

13. Bahmanpour, A. M. et al. Cu-Al Spinel as a Highly Active and Stable Catalyst for the Reverse Water Gas Shift Reaction. ACS Catal. 9, 6243-6251 (2019).

14. Zhang, $\mathrm{X}$. et al. Highly Dispersed Copper over $\beta-\mathrm{Mo}_{2} \mathrm{C}$ as an Efficient and Stable Catalyst for the Reverse Water Gas Shift (RWGS) Reaction. ACS Catal. 7, 912-918 (2016).

15. Zhang, Q., Pastor-Pérez, L., Jin, W., Gu, S. \& Reina, T. R. Understanding the promoter effect of $\mathrm{Cu}$ and $\mathrm{Cs}$ over highly effective $\beta-\mathrm{Mo}_{2} \mathrm{C}$ catalysts for the reverse water-gas shift reaction. Appl. Catal. B: Environ. 244, 889-898 (2019)

16. $\mathrm{Fu}, \mathrm{X}$. et al. $\mathrm{Co}_{3} \mathrm{O}_{4}-\mathrm{Al}_{2} \mathrm{O}_{3}$ mesoporous hollow spheres as efficient catalyst for Fischer-Tropsch synthesis. Appl. Catal. B: Environ. 211, 176-187 (2017).

17. Ashwell, A. P. et al. Hydrogenation of $\mathrm{CO}$ to Methanol on $\mathrm{Ni}(110)$ through Subsurface Hydrogen. J. Am. Chem. Soc. 139, 17582-17589 (2017).

18. Williamson, D. L., Herdes, C., Torrente-Murciano, L., Jones, M. D. \& Mattia, D. N-Doped Fe@CNT for Combined RWGS/FT CO 2 Hydrogenation. ACS Sustain. Chem. Eng. 7, 7395-7402 (2019).

19. Su, X., Yang, X., Zhao, B. \& Huang, Y. Designing of highly selective and hightemperature endurable RWGS heterogeneous catalysts: recent advances and the future directions. J. Energy Chem. 26, 854-867 (2017).

20. Chen, C. Study of iron-promoted $\mathrm{Cu} / \mathrm{SiO}_{2}$ catalyst on high temperature reverse water gas shift reaction. Appl. Catal. A: General. 257, 97-106 (2004).

21. Zhao, Z. et al. Atomically dispersed $\mathrm{Pt} / \mathrm{CeO}_{2}$ catalyst with superior $\mathrm{CO}$ selectivity in reverse water gas shift reaction. Appl. Catal. B: Environ. 291, 120101 (2021)

22. Yang, X. et al. Promotion effects of potassium on the activity and selectivity of $\mathrm{Pt} /$ zeolite catalysts for reverse water gas shift reaction. Appl. Catal. B: Environ. 216, 95-105 (2017).

23. Ronda-Lloret, M., Rico-Francés, S., Sepúlveda-Escribano, A. \& RamosFernandez, E. V. $\mathrm{CuO}_{\mathrm{x}} / \mathrm{CeO}_{2}$ catalyst derived from metal organic framework for reverse water-gas shift reaction. Appl. Catal. A: General. 562, 28-36 (2018).

24. Vovchok, D. et al. Deciphering Dynamic Structural and Mechanistic Complexity in $\mathrm{Cu} / \mathrm{CeO}_{2}$ /ZSM-5 Catalysts for the Reverse Water-Gas Shift Reaction. ACS Catal. 10, 10216-10228 (2020).

25. Chen, A. et al. Structure of the catalytically active copper-ceria interfacial perimeter. Nat. Catal. 2, 334-341 (2019).

26. Si, R. et al. Structure sensitivity of the low-temperature water-gas shift reaction on $\mathrm{Cu}-\mathrm{CeO}_{2}$ catalysts. Catal. Today 180, 68-80 (2012).

27. Yu, W. et al. Construction of Active Site in a Sintered Copper-Ceria Nanorod Catalyst. J. Am. Chem. Soc. 141, 17548-17557 (2019).

28. Yang, S. et al. Synergy between Ceria Oxygen Vacancies and $\mathrm{Cu}$ Nanoparticles Facilitates the Catalytic Conversion of $\mathrm{CO}_{2}$ to $\mathrm{CO}$ under Mild Conditions. ACS Catal. 8, 12056-12066 (2018).

29. Aneggi, E., Wiater, D., de Leitenburg, C., Llorca, J. \& Trovarelli, A. ShapeDependent Activity of Ceria in Soot Combustion. ACS Catal. 4, 172-181 (2013).

30. Wang, W. et al. Highly Dispersed Copper Oxide Clusters as Active Species in Copper-Ceria Catalyst for Preferential Oxidation of Carbon Monoxide. ACS Catal. 5, 2088-2099 (2015).

31. Wang, W. et al. Crystal Plane Effect of Ceria on Supported Copper Oxide Cluster Catalyst for CO Oxidation: Importance of Metal-Support Interaction. ACS Catal. 7, 1313-1329 (2017).

32. Yan, $\mathrm{H}$. et al. Promoted $\mathrm{Cu}-\mathrm{Fe}_{3} \mathrm{O}_{4}$ catalysts for low-temperature water gas shift reaction: Optimization of $\mathrm{Cu}$ content. Appl. Catal. B: Environ. 226, 182-193 (2018)

33. Sripada, $\mathrm{P}$. et al. Investigating the dynamic structural changes on $\mathrm{Cu} / \mathrm{CeO}_{2}$ catalysts observed during $\mathrm{CO}_{2}$ hydrogenation. J. Catal. 381, 415-426 (2020)

34. Kang, L. et al. The Electrophilicity of Surface Carbon Species in the Redox Reactions of CuO-CeO ${ }_{2}$ Catalysts. Angew. Chem. Int. Ed. 60, 14420-14428 (2021).

35. Elias, J. S. et al. Elucidating the Nature of the Active Phase in Copper/Ceria Catalysts for CO Oxidation. ACS Catal. 6, 1675-1679 (2016).

36. Kang, L. et al. Adsorption and activation of molecular oxygen over atomic copper(I/II) site on ceria. Nat. Commun. 11, 4008 (2020).

37. Geng, Z. et al. Oxygen Vacancies in $\mathrm{ZnO}$ Nanosheets Enhance $\mathrm{CO}_{2}$ Electrochemical Reduction to CO. Angew. Chem. Int. Ed. 57, 6054-6059 (2018).

38. Bobadilla, L. F., Santos, J. L., Ivanova, S., Odriozola, J. A. \& Urakawa, A. Unravelling the Role of Oxygen Vacancies in the Mechanism of the Reverse Water-Gas Shift Reaction by Operando DRIFTS and Ultraviolet-Visible Spectroscopy. ACS Catal. 8, 7455-7467 (2018).

39. Yang, S. et al. Oxygen Vacancy Engineering of Cerium Oxides for Carbon Dioxide Capture and Reduction. ChemSusChem 6, 1326-1329 (2013).

40. Vindigni, F., Manzoli, M., Damin, A., Tabakova, T. \& Zecchina, A. Surface and Inner Defects in $\mathrm{Au} / \mathrm{CeO}_{2}$ WGS Catalysts: Relation between Raman Properties, Reactivity and Morphology. Chem.- A Eur. J. 17, 4356-4361 (2011). 
41. Wu, Z., Li, M., Howe, J., Meyer, H. M. \& Overbury, S. H. Probing Defect Sites on $\mathrm{CeO}_{2}$ Nanocrystals with Well-Defined Surface Planes by Raman Spectroscopy and $\mathrm{O}_{2}$ Adsorption†. Langmuir 26, 16595-16606 (2010).

42. Wang, $\mathrm{H}$. et al. Roles of oxygen vacancy and $\mathrm{O}$ - in oxidation reactions over $\mathrm{CeO}_{2}$ and $\mathrm{Ag} / \mathrm{CeO}_{2}$ nanorod model catalysts. J. Catal. 368, 365-378 (2018).

43. Huang, W. \& Gao, Y. Morphology-dependent surface chemistry and catalysis of $\mathrm{CeO}_{2}$ nanocrystals. Catal. Sci. Technol. 4, 3772-3784 (2014).

44. Dai, B., Cao, S., Xie, H., Zhou, G. \& Chen, S. Reduction of $\mathrm{CO}_{2}$ to $\mathrm{CO}$ via reverse water-gas shift reaction over $\mathrm{CeO}_{2}$ catalyst. Korean. J. Chem. Eng. 35, 421-427 (2018).

45. Chen, X. et al. Identification of relevant active sites and a mechanism study for reverse water gas shift reaction over $\mathrm{Pt} / \mathrm{CeO}_{2}$ catalysts. J. Energy Chem. 25, 1051-1057 (2016).

46. Zhang, Y. et al. Highly efficient $\mathrm{Cu} / \mathrm{CeO}_{2}$-hollow nanospheres catalyst for the reverse water-gas shift reaction: Investigation on the role of oxygen vacancies through in situ UV-Raman and DRIFTS. Appl. Surf. Sci. 516, 146035 (2020).

47. Zhang, X. et al. Synergy between $\beta-\mathrm{Mo}_{2} \mathrm{C}$ Nanorods and Non-thermal Plasma for Selective $\mathrm{CO}_{2}$ Reduction to CO. Chem 6, 3312-3328 (2020).

48. Zonetti, P. C. et al. The $\mathrm{Ni}_{x} \mathrm{Ce}_{0.75} \mathrm{Zr}_{0.25-x} \mathrm{O}_{2}$ solid solution and the RWGS. Appl. Catal. A: General. 475, 48-54 (2014).

49. Wang, W. et al. Reverse water gas shift over $\mathrm{In}_{2} \mathrm{O}_{3}-\mathrm{CeO}_{2}$ catalysts. Catal. Today 259, 402-408 (2016).

50. Wang, L. et al. Dispersed Nickel Boosts Catalysis by Copper in $\mathrm{CO}_{2}$ Hydrogenation. ACS Catal. 10, 9261-9270 (2020).

51. Yu, Y. et al. Highly active and stable copper catalysts derived from copper silicate double-shell nanofibers with strong metal-support interactions for the RWGS reaction. Chem. Commun. 55, 4178-4181 (2019).

52. Chen, $\mathrm{X}$. et al. Catalytic performance of the $\mathrm{Pt} / \mathrm{TiO}_{2}$ catalysts in reverse water gas shift reaction: Controlled product selectivity and a mechanism study. Catal. Today 281, 312-318 (2017).

53. Kim, S. S., Lee, H. H. \& Hong, S. C. A study on the effect of support's reducibility on the reverse water-gas shift reaction over Pt catalysts. Appl. Catal. A: General. 423-424, 100-107 (2012).

54. Rodrigues, $\mathrm{M}$. T. et al. RWGS reaction employing $\mathrm{Ni} / \mathrm{Mg}(\mathrm{Al}, \mathrm{Ni}) \mathrm{O}-\mathrm{The}$ role of the O vacancies. Appl. Catal. A: General. 543, 98-103 (2017).

55. Xiong, K. et al. $\mathrm{CO}_{2}$ Reverse Water-Gas Shift Reaction on Mesoporous $\mathrm{M}-\mathrm{CeO}_{2}$ Catalysts. Can. J. Chem. Eng. 95, 634-642 (2017).

\section{Acknowledgements}

This work was financially supported from the National Science Foundation of China (Grant No. 21771117, 21805167, 22075166), the Taishan Scholar Project of Shandong Province of China, the Young Scholars Program of Shandong University (Grant No. 11190089964158), the Outstanding Youth Scientist Foundation of Hunan Province (Grant No. 2020JJ2001), and the Key Project of Educational
Department of Anhui Province (Grant No. KJ2019A0861). We thank the Center of Structural Characterizations and Property Measurements at Shandong University for the help on sample characterizations.

\section{Author contributions}

C.J.J. and C.M. supervised the work; H.X.L. and C.J.J. designed the experiments, analyzed the results and wrote the manuscript; S.Q.L. made the DFT calculations; H.X.L. and W.W.W. performed the in situ DRIFTS, in situ Raman; H.X.L. and W.Z.Y. performed the catalysts preparation, catalytic tests and the TPR tests; W.J.Z. and C.M. performed the aberration-corrected HAADF-STEM measurements and analyzed the results.

\section{Competing interests}

The authors declare no competing interests.

\section{Additional information}

Supplementary information The online version contains supplementary material available at https://doi.org/10.1038/s41467-022-28476-5.

Correspondence and requests for materials should be addressed to Chao Ma or ChunJiang Jia.

Peer review information Nature Communications thanks the anonymous reviewers for their contribution to the peer review of this work. Peer reviewer reports are available.

Reprints and permission information is available at http://www.nature.com/reprints

Publisher's note Springer Nature remains neutral with regard to jurisdictional claims in published maps and institutional affiliations.

Open Access This article is licensed under a Creative Commons Attribution 4.0 International License, which permits use, sharing, adaptation, distribution and reproduction in any medium or format, as long as you give appropriate credit to the original author(s) and the source, provide a link to the Creative Commons license, and indicate if changes were made. The images or other third party material in this article are included in the article's Creative Commons license, unless indicated otherwise in a credit line to the material. If material is not included in the article's Creative Commons license and your intended use is not permitted by statutory regulation or exceeds the permitted use, you will need to obtain permission directly from the copyright holder. To view a copy of this license, visit http://creativecommons.org/ licenses/by/4.0/.

(c) The Author(s) 2022 